\title{
El turismo comunitario como iniciativa de desarrollo local. Caso localidades de Ciudad Bolívar y Usme zona rural de Bogotát
}

\author{
Rosalía Burgos Doria ${ }^{* *}$
}

Recibido: 5 de noviembre de 2015

Evaluado: 20 de enero de 2016 Aceptado: 14 de febrero de 2016

\section{Resumen}

El presente artículo de revisión bibliográfica pretende identificar los estudios que se han realizado en torno al desarrollo del turismo comunitario en algunos países de Latinoamérica y determinar cuál ha sido la contribución al mejoramiento de la calidad de vida de las comunidades que lo han adelantado. Esto con el fin de construir un marco referencial de base al proyecto de la investigación en curso adscrito al grupo interinstitucional GIRSA, cuyo propósito es impulsar el turismo comunitario como un motor de desarrollo para la consolidación de los destinos turísticos de las localidades de Ciudad Bolívar y Usme (zona rural) en Bogotá D.C. En este sentido, las referencias consultadas corresponden a investigaciones y proyectos adelantados en contextos rurales, por organizaciones del sector público, privado y la academia, comprendidos entre el periodo de 2006 a 2015 en algunos países latinoamericanos.

Por otra parte, se abordan las distintas normas y políticas que se han elaborado sobre el turismo en Colombia y cómo estas han contribuido para el desarrollo del turismo comunitario; se

Artículo de revisión. Resultado del proyecto de investigación titulado Turismo comunitario como motor de desarrollo. Caso Localidades de Ciudad Bolivar y Usme, zona Rural de Bogotá D.C., financiado por la Fundación Universitaria Los Libertadores. Cómo citar este artículo: Burgos Doria, R. (2016). El turismo comunitario como iniciativa de desarrollo local. Caso localidades de Ciudad Bolívar y Usme zona rural de Bogotá. Hallazgos, 13(26), 193-214 (doi: http://dx.doi.org/10.15332/s1794-3841.2016.0026.08).

** M. Sc. en Desarrollo Sostenible y Medio Ambiente. Docente de tiempo completo de la Fundación Universitaria Los Libertadores e investigadora del grupo interinstitucional GIRSA, avalado por Colciencias en categoría C. Correo electrónico: rburgosd@libertadores.edu.co, rosaliaburgos23@hotmail.com. Carrea $16 \# 63^{a}$-48. Bogotá D.C. 
evidencian casos que en la actualidad son apoyados por el Gobierno nacional a través de cooperación internacional, también se presentan las recientes dinámicas urbano-rurales del distrito capital de Bogotá, al igual que la caracterización de las localidades que hacen parte del proyecto de investigación mencionado.

Palabras clave: desarrollo y libertad, turismo comunitario, desarrollo a escala humana. 


\section{Community tourism as local development initiative. Case Ciudad Bolívar and Usme Bogotá rural area}

Received: November 5, 2015

Evaluated: January 20, 2016 Accepted: February 14, 2016

\section{Abstract}

This literature review article aims to identify studies that have been done on the development of community tourism in some countries of Latin America and determine what has been the contribution to improving the quality of life of the communities that have been advanced; this in order to build a framework based on the draft of the ongoing investigation GIRSA assigned to interagency group whose purpose is to promote community tourism as an engine of development for the consolidation of the tourist destinations in the towns of Ciudad Bolivar Usme (rural area) in Bogota. In this sense, the consulted references are to research and developed projects in rural contexts, public organizations, private sector and academia, including from the period from 2006 to 2015 in some Latin American countries.

Moreover, the various rules and policies that have been developed on tourism in Colombia, as they have contributed to the development of community tourism issues; cases today by the national government are supported through international cooperation are evident, recent urban-rural capital district of Bogota, like the characterization of the towns that make up the research project mentioned dynamics is also presented

Keywords: Development as freedom, community tourism, development at human scale. 


\section{O turismo comunitário como iniciativa de desenvolvimento local. Caso localidades de Ciudad Bolívar e Usme zona rural de Bogotá}

\section{Resumo}

O presente artigo de revisão bibliográfica pretende identificar os estudos que se tem realizado sobre o desenvolvimento do turismo comunitário em alguns países de Latinoamérica e determinar qual tem sido a contribuição ao melhoramento da qualidade de vida das comunidades que o tem feito. Isto com o objetivo de construir um ponto de referência como base ao projeto da pesquisa em curso adscrito ao grupo interinstitucional GIRSA, cujo proposito é impulsar o turismo comunitário como um motor de desenvolvimento para a consolidação dos destinos turísticos das localidades de Ciudad Bolivar e Usme (zona rural) em Bogotá D.C. Neste sentido, as referencias consultadas correspondem a pesquisas e projetos adiantados em contextos rurais por organizações do setor público, privado e academia, compreendidos entre o período de 2006 a 2015 em alguns países latino-americanos. Por outro lado, abordam-se as distintas normas e políticas que se tem elaborado sobre o turismo na Colômbia e como estas tem contribuído para o desenvolvimento do turismo comunitário; evidenciam-se casos que na atualidade são apoiados pelo Governo nacional através da cooperação internacional, também se apresentam as recentes dinâmicas urbano-rurais do distrito capital de Bogotá, ao igual que a caracterização das localidades que fazem parte do projeto de pesquisa mencionado.

Palavras-chave: desenvolvimento e liberdade, turismo comunitário, desenvolvimento à escala humana
Recebido: 5 de novembro de 2015

Avaliado: 20 de janeiro de 2015

Aceito: 14 de fevereiro de 2016 


\section{INTRODUCCIÓN}

El turismo muchas veces se presenta como uno de los principales sectores para generar desarrollo y crecimiento económico en la población local que lo impulsa. Los impactos que se presentan, por su crecimiento de una manera indiscriminada y sin un control adecuado pueden ser desfavorables para determinados sectores de la población, especialmente la más desfavorecida; además, puede causar deterioro a los recursos naturales y culturales que posee. En este sentido, el turismo que actualmente se estimula a nivel mundial es aquel en el cual la población local participa de su planificación, gestión y promoción. En este orden de ideas, el turismo comunitario como lo expone Maldonado (2005) “es toda forma de organización empresarial sustentada en la propiedad y la autogestión de los recursos patrimoniales comunitarios; contribuye a la solidaridad en el trabajo y distribución de los beneficios generados por la prestación de servicios turísticos" (p. 5), el cual busca fomentar encuentros interculturales con los visitantes. Es un reto y una oportunidad que contribuye con el desarrollo de las comunidades, y les proporciona así ingresos adicionales que mejoran la calidad de vida. También se debe concebir como una oportunidad para establecer eficientes mecanismos de organización y autogestión, a los efectos de preservar el patrimonio natural y cultural, costumbres y formas de vida de las propias comunidades (Garcia, 2006).

En América Latina, el turismo comunitario es un fenómeno que data de las dos últimas décadas y surge en un contexto de grandes cambios económicos, sociales y políticos, como son la dinámica comercial y financiera, los nuevos paradigmas del desarrollo sostenible y la responsabilidad social de las empresas, entre otras, donde la importancia del paisaje, los diferentes atractivos culturales y la vida silvestre que se encuentra es sus territorio han permitido que los Gobiernos se preocupen por impulsarlo, en especial en zonas rurales como alternativa de desarrollo económico y social (Organización Internacional del Trabajo [OIT], 2008).

En este orden de ideas, en Colombia el desarrollo turístico se enfoca en una mayor interacción de las regiones, lo que conduce al incremento en la oferta de los destinos, a que se promueva la generación de empleo, se fortalezca la cadena de valor; dota además de herramientas de emprendimiento a los pobladores para que logren ser gestores de su propio proceso y por último contribuyan con el cuidado del ambiente en su territorio (Burgos Doria, 2015). Por consiguiente, el turismo comunitario se viene desarrollando como proceso alternativo en el cual se valoren y se rescaten los atractivos locales y la identidad territorial, con el fin de buscar el beneficio de las comunidades menos favorecidas.

Este artículo tiene como propósito identificar los estudios que se han realizado en torno al desarrollo del turismo comunitario en algunos países de Latinoamérica y determinar cuál ha sido la contribución al mejoramiento de la calidad de vida de las comunidades que lo desarrollan. Para ello, se hace una revisión de fuentes secundarias de investigaciones y proyectos realizados en estos países por organizaciones del sector público, como el sector de la academia, comprendidas a partir de 2006 hasta 2015 $\mathrm{y}$ en contextos rurales. Adicionalmente, 
se presenta un análisis de los documentos que permiten servir de base teórica para la orientación de un proyecto de investigación que busca responder a la siguiente pregunta: ¿cómo impulsar el turismo comunitario como un motor de desarrollo para la consolidación de los destinos turísticos de las localidades de Ciudad Bolívar y Usme (zona rural) en Bogotá D.C.?

En el documento se hallarán las teorías acordes al desarrollo de comunidades, como es el caso dela teoría del desarrollo a escala humana de Max Neef y la teoría de desarrollo y libertad de Amrtya Sen. Por otra parte, se encontrará el proceso normativo desarrollado en Colombia alrededor del turismo y específicamente del turismo comunitario; al igual que los proyectos financiados por el Gobierno nacional. Por último, se hace una caracterización de las localidades objeto de estudio del proyecto de investigación mencionado en el párrafo anterior.

\section{Aportes teóricos del desarrollo}

En la actualidad, los esfuerzos por establecer un Nuevo Orden Económico Internacional (NOEI) y una nueva división internacional del trabajo no han permitido construir las relaciones de dependencia económica, financiera, tecnológica y cultural de los países en vía de desarrollo con respecto a las naciones industrializadas. Las pautas de consumo que imponen estas naciones desarrolladas agudizan su dependencia, perpetúan sus desequilibrios internos, amenazan su identidad cultural y son estos países los que controlan la producción y comercialización de los productos e insumos que se presentan en el mercado (Max-Neef, 1993).
En este sentido, Max-Neef (1998) establece que se deben diseñar y utilizar tecnologías que se ajusten a un proceso de desarrollo verdaderamente ecohumanista que pueda garantizar la sustentabilidad de los recursos naturales para el futuro (p.87). Este autor establece que el desarrollo social y el desarrollo individual no puede darse por separado y que el desarrollo a escala humana ha de estimular la construcción de sujetos sociales capaces de sostener un desarrollo autónomo, autosustentado y armónico en sus diversos ámbitos. Considera, además, que deben configurar redes horizontales, desarrollar acciones de apoyo mutuo, articular prácticas individuales y grupales para presentar proyectos compartidos en los que se debe apuntar a la autodependencia local, potenciar el uso de los recursos convencionales, apuntar a la conformación de organizaciones, asociaciones, movimientos juveniles y de mujeres entre otros (Max-Neef, 1993).

Por su parte el Programa de las Naciones Unidas para el Desarrollo [PNUD] (1990) considera que el desarrollo humano es un proceso mediante el cual se ofrece a las personas mayores oportunidades; entre las más importantes está tener una vida prolongada y saludable, educación y acceso a los recursos necesarios para conseguir un nivel de vida decente, en el cual la libertad política, la garantía de los derechos humanos y el respeto a sí mismo son factores importantes para su logro. De esta manera, el desarrollo por lo menos debe crear un ambiente propicio para que las personas, tanto individual como colectivamente potencialicen sus oportunidades para así llevar una vida productiva, creativa conforme a sus necesidades e intereses. En este sentido, Arriola (2007) expone que el desarrollo humano “es 
el proceso que permite ampliar las opciones de las personas, opciones que pueden ser infinitas y cambiables, asumiendo que las personas también valoran logros que no aparecen del todo, o de forma inmediata" (p. xv).

Por otra parte Sen (2000) propone que el desarrollo puede concebirse como un proceso de expansión de las libertades reales que disfruta el individuo (p.19), donde las libertades humanas se relacionan con el crecimiento del producto nacional bruto, con el aumento de las rentas personales, con la industrialización y con la modernización social. Adicionalmente, la libertad es el derecho que tiene el individuo a la educación, a la salud, a participar en debates y escrutinios públicos y para lograrla se debe concebir como un fin y no como el medio, y para lograr el desarrollo en las regiones se deben eliminar las principales barreras de libertad como la pobreza, la tiranía, la escasez de oportunidad económica, la privación social, el abandono de los servicios públicos y la intolerancia en la que se encuentran muchas veces las regiones y pueblos (Sen, 2000).

El desarrollo humano debe lograr la ampliación de las opciones de la gente en lo socialmente deseable y técnicamente posible, de una manera equitativa, participativa y sostenible. La equidad y la libertad son características instrumentales y constitutivas del desarrollo (PNUD, 2005).

Por consiguiente, la contribución del turismo al desarrollo de la población debe lograr con esta actividad no solo crecimiento económico, sino también un motor de progreso para la población, ya sea en entornos rurales, urbanos y silvestres, entre otros. Por su parte, el turismo comunitario permite la integración de la comunidad, la cual ejerce un papel significativo en la autogestión de los recursos, son dueños, gestores y beneficiarios de la iniciativa con el objetivo de lograr equidad social (Jiménez, 2014). La comunidad ofrece al visitante los recursos naturales y culturales con que cuenta, el compartir las actividades diarias y el deleite de los productos gastronómicos con que cuentan, todo esto con el propósito de obtener recursos adicionales que permitan aumentar sus ingresos económicos.

\section{Amanera de investigaciones EN TORNO AL TURISMO COMUNITARIO}

En América Latina se vienen impulsando proyectos de turismo comunitario con el fin de promover el desarrollo de las comunidades locales, entre las que se pueden resaltar está el desarrollado por los siguientes investigadores: en Ecuador, Cabanilla (2015) y Santana y Atiencia (2013) en Bolivia; Maydana y Lima (2012), Cox (2009); en Venezuela, Guzmán, Borges y Castillo (2011),en Argentina, Morales (2006), y Román y Ciccolella (2009) en México; Barrera y Alvarado (2009); Suárez, Bribiescas y Villanieva (2013) en Chile; Skewes, Henríquez y Pilquimán (2012), Casas, Domingo y Pastor (2012); en Nicaragua, Cañada y Fandiño (2009), Torres Obando (2015), Guzmán y Cañizares (2009) en Perú, Montoya (2013) y Pastor, Jurado y Domingo (2011); en Costa Rica, Nel-Lo (2008), y Salas (2011); en Brasil y Rodrigues, Corbari, Cioce y Jurema (2014) y Helmsing y Fonseca(2011), Pastor, Gómez y Espeso (2012), Neide y Cioce (2013); en Panamá, Villete (2012); Fundación Codespa (2013), Yanza (2012), Montoya (2013). En este sentido, se exponen a continuación algunas de las investigaciones desarrolladas (ver tabla 1). 
Tabla 1. Investigaciones desarrolladas en torno al turismo comunitario en algunos países latinoamericanos

\begin{tabular}{l}
\hline Nombre de la investigación \\
\hline Turismo Comunitario y Desarro- \\
llo Local. Interacción y escala- \\
miento deInnovación. Instituto \\
de Estudios Peruanos- IEP. Lima- \\
perú: primera edición. Por Maria \\
Paz Montoya
\end{tabular}

Metodología
El estudio es de tipo descriptivo,
desarrollo del turismo comuni-
tario en algunas zonas de Perú
como son: el Valle del Colca en
Arequipa, la experiencia de Mara
en Cusco y la de Posada Amazo-
nas en el departamento de Madre
de Dios en la selva del Perú, los
cuales fueron apoyados por el
gobierno del Perú a través del
IEP con el propósito de generar
inclusión económica y social al
desarrollo de las zonas.

Resultados y/o conclusiones

En las tres regiones en donde se implementó el turismo comunitario se pudo evidenciar procesos de innovación que madura progresivamente y alcanzan resultados positivos en las comunidades rurales en el mediano y largo plazo. Por otra parte se fortalecieron y se construyeron relaciones entre los actores que realizan esta dinámica a través del intercambio, el manejo de los conflictos, la negociación de los intereses, se establecieron objetivos comunes que contribuyan al avance de la iniciativa.

\begin{tabular}{ll}
\hline Nombre de la investigación & Metodología \\
\hline $\begin{array}{l}\text { Turismo comunitario: Una alter- } \\
\text { nativa de desarrollo indigena. }\end{array}$ & El proyecto se desarrolló en dos \\
Por Hector Fredy Morales & Fase formativa: la cual estuvo \\
& dirigida principalmente a la capa- \\
& citación de líderes atacamañeros \\
& y quechuas. Y Fase productiva: \\
& que estuvo orientada a la asisten- \\
& cia técnica en ámbitos de gestión \\
& y administración de empresas de \\
& turismo comunitario
\end{tabular}

Resultados y/o Conclusiones

Se desarrollaron proyectos de gestión ambiental, micro proyectos ambientales donde participaron estudiantes, profesores y apoderados. Y por último se elaboraron proyectos de capacitación en temas relacionados con el comercio turístico con un enfoque ecológico y comunitario que derivaron en planes de negocio asociados a infraestructura turística de carácter comunitariocasas de huésped, senderismo y miradores.

\begin{tabular}{|c|c|c|}
\hline Nombre de la investigación & Metodología & Resultados y/o Conclusiones \\
\hline $\begin{array}{l}\text { Gestión y fortalecimiento de } \\
\text { proyectos comunitarios: una } \\
\text { opción para el desarrollo turís- } \\
\text { tico sostenible en comunidades } \\
\text { rurales del estado de Chihuahua } \\
\text { (caso Ejido ojo de la casa). Por: } \\
\text { Rosa Suarez, Francisco Bribiescas } \\
\text { y Jorge Villanueva }\end{array}$ & $\begin{array}{l}\text { La metodología utilizada es de } \\
\text { tipo documental y descriptivo. } \\
\text { Donde se hizo: } \\
\text { Análisis del entorno ambien- } \\
\text { tal, sociocultural, político y } \\
\text { económico. } \\
\text { Se analizó el mercado turístico } \\
\text { (oferta y demanda) } \\
\text { Estudio técnico que incluye el } \\
\text { diseño de productos y servicios } \\
\text { turísticos. } \\
\text { Estudio financiero } \\
\text { Plan de promoción y comerciali- } \\
\text { zación del proyecto. }\end{array}$ & $\begin{array}{l}\text { En esta investigación se propuso } \\
\text { desarrollar actividades ecoturís- } \\
\text { tica a través de programas para } \\
\text { el rescate de la flora y fauna, ob- } \\
\text { servación de fósiles, observación } \\
\text { de ecosistemas que se encuentran } \\
\text { el lugar, observación sideral, sen- } \\
\text { deros interpretativos, caminatas, } \\
\text { escaladas en roca y cabalgata. } \\
\text { Actividades rurales como: talle- } \\
\text { res artesanales, aprendizaje rural } \\
\text { (museo), talleres gastronómicos. } \\
\text { Actividad Agroturística como: } \\
\text { siembra de hortaliza. Con el } \\
\text { propósito de brindar una oferta } \\
\text { turística orientada a las activida- } \\
\text { des de ecoturismo, turismo de } \\
\text { aventura y turismo rural. }\end{array}$ \\
\hline
\end{tabular}




\begin{tabular}{|c|c|c|}
\hline Nombre de la investigación & Metodología & Resultados y/o Conclusiones \\
\hline $\begin{array}{l}\text { Impactos culturales del turismo } \\
\text { comunitario en Ecuador sobre } \\
\text { el rol del chamán y los ritos } \\
\text { mágico-religiosos: Por Enrique } \\
\text { Cabinilla }\end{array}$ & $\begin{array}{l}\text { La metodología utilizada es de } \\
\text { tipo explicativa por cuanto se } \\
\text { plantea determinar las relacio- } \\
\text { nes causa-efecto del turismo } \\
\text { comunitario en Ecuador sobre } \\
\text { el rol del chamán y los ritos má- } \\
\text { gico-religiosos. Se primó el uso } \\
\text { del método mixto (cuantitativo } \\
\text { y cualitativo) como una alterna- } \\
\text { tiva coherente y alineada a los } \\
\text { objetivos }\end{array}$ & $\begin{array}{l}\text { Se evidencia un impacto nega- } \\
\text { tivo en el rol del chamán por la } \\
\text { oferta de experiencias ligadas al } \\
\text { consumo de alucinógenos como } \\
\text { la ayahuasca. Por otra parte este } \\
\text { tipo de actividades se deben ofre- } \\
\text { cer con mucho cuidado al turista, } \\
\text { por consiguiente las comunida- } \\
\text { des deben contar con asistencia } \\
\text { técnica para crear centros de ges- } \\
\text { tión cultural, independientes del } \\
\text { turismo, que regulen el uso de los } \\
\text { recursos culturales y establezcan } \\
\text { indicadores para monitorear per- } \\
\text { manentemente posibles impactos } \\
\text { irreversibles. }\end{array}$ \\
\hline
\end{tabular}

\begin{tabular}{l}
\hline Nombre de la investigación \\
\hline Turismo sostenible, cadena de \\
valor y participación comunita- \\
ria en suesca (cundinamarca), \\
Colombia. Por: Edgar Moreno y \\
Fredy Ochoa.
\end{tabular}

Colombia

Metodología

La metodología utilizada fue de tipo descriptivo, partiendo deun análisiscon base a cuatro criterios y cinco indicadores derivados de las teorías de desarrollo como expansión de la libertad y la teoría a escala humana, en un caso específico de aplicación del modelo, a partir de la revisión de informes y experiencias de su puesta en marcha.

\section{Resultados y/o Conclusiones}

A pesar que no se logró un empoderamiento efectivo de las comunidades de base en la actividad turística de Suesca, si se estableció un proyecto a largo plazo. En estas condiciones el Modelo Cadena de Valor contribuyó al mejoramiento del bienestar de la comunidad vinculada al proceso.

\begin{tabular}{|c|c|c|}
\hline Nombre de la investigación & Metodología & Resultados y/o Conclusiones \\
\hline $\begin{array}{l}\text { Turismo comunitario, como es- } \\
\text { trategias para el empoderamiento } \\
\text { comunitario en las localidades de } \\
\text { Ciudad Bolívar, Usme y Suma- } \\
\text { paz, zona rural. Bogotá D.C. Por: } \\
\text { Rosalía Burgos y Martha Nubia } \\
\text { Cardona }\end{array}$ & $\begin{array}{l}\text { El tipo de investigación es una } \\
\text { Investigación Acción Participa- } \\
\text { ción-IAP, mediante la cual se } \\
\text { observaron problemas y caracte- } \\
\text { rísticas particulares del territorio. }\end{array}$ & $\begin{array}{l}\text { En cada localidad se observaron } \\
\text { oportunidades, problemas y } \\
\text { características particulares, el } \\
\text { turismo comunitario es un pro- } \\
\text { ducto nuevo, por consiguiente, la } \\
\text { administración local y la comu- } \\
\text { nidad tiene la coyuntura de plan- } \\
\text { tear estrategias concertadas para } \\
\text { el desarrollo de la cooperación } \\
\text { horizontal, con ejes transversales } \\
\text { comunes a los diferentes sistemas } \\
\text { de gestión pública y privada }\end{array}$ \\
\hline
\end{tabular}

Fuente: Elaboración propia.

Como podemos observar en los diferentes proyectos y estudios mencionados anteriormente, las comunidades que lo desarrollan han sido capacitadas, orientadas y apoyadas por el Gobierno y la academia, entre otros, para el desarrollo del turismo comunitario, lo que ha permitido que las comunidades sean más conscientes de la importancia de cuidar su territorio y sus recursos naturales y culturales. También se 
evidencia que no todas las actividades de turismo comunitario presentan resultados positivos, lo que permite que existan una mayor vigilancia y orientación del estado al igual que las organizaciones privadas.

\section{Turismo en Colombia}

\section{Desarrollos normativos}

Inicialmente, en Colombia las políticas que se aplicaban al sector turístico estaban sujetas a referentes internacionales. Es con la Constitución Política de 1991 como se empezaron a diseñar estrategias que contribuyeron con al desarrollo de la actividad, buscando siempre que el avance estuviera acorde con el cuidado del ambiente y la salvaguardia del patrimonio. Esto permitió que se elaboraran leyes en el sector, con el propósito de brindar herramientas que apoyaran al desarrollo de dicho sector y de esta manera poder direccionar la actividad, como es el caso:

- Ley 300 de 1996, "Ley General de Turismo", la cual estableció los primeros parámetros para regular la actividad, involucrando al Estado, al sector privado, gremios y operadores turísticos, entre otros.

- Ley 1101 de 2006, la cual hace algunas modificaciones a la Ley 300 de 1996 y con esta se crea el Viceministerio de Turismo, el cual está adscrito al Ministerio de Comercio Industria y Turismo.

- Ley 397 de 1997, “Ley General de la Cultura", la cual buscó establecer los primos lineamientos institucionales direccionados a la salvaguarda del patrimonio cultural material.
- Ley 1185 de 2008, esta buscó implementar lineamientos para la salvaguarda del patrimonio cultural inmaterial y a la vez modificó algunos artículos de la Ley 397 de 1997.

- Ley 1558 de 2012, con la elaboración de esta ley se logró derogar y modificar algunos artículos de la Ley General del Turismo, con el fin de contextualizarlo con los distintos cambios en los que se ha envuelto el sector en la actualidad.

De tal modo, con el Gobierno nacional, a partir de 2002 con la Política de Seguridad Democrática, el Estado colombiano inicia el proceso de elaborar políticas que tienen como objetivo mejorar la competitividad de los destinos y los productos, y acrecentar la participación de la comunidad en la prestación de los servicios turísticos. Se busca con estas políticas proporcionarles herramientas que contribuyan al aumento en sus ingresos; a su vez, se logra una distribución más equitativa y la mejora en la calidad de vida de la población (Movimiento ovor Colombia, 2011).

En Colombia se han venido elaborando políticas que han permitido fortalecer el desarrollo del turismo comunitario, entre las que se pueden resaltar:

- Los lineamientos para el ecoturismo comunitario en Colombia (2006): buscan la participación de las comunidades locales en la gestión de sus destinos y recursos. Como estrategias de sostenibilidad a nivel ambiental y sociocultural.

- $\quad$ Política de turismo de naturaleza (2012): busca valorar el patrimonio natural de la nación, y que permita generar 
productos turísticos competitivos en los cuales la participación de las comunidades locales es de vital importancia.

- Lineamientos de políticas para el desarrollo de turismo comunitario (2012): busca fortalecer y dotar de herramientas a los destinos y a los emprendimientos, para que logren ser gestores de su propio desarrollo, y obtener así los conocimientos necesarios (Calderón, 2013).

Adicionalmente, a través de los distintos planes de desarrollo nacional, como el Plan de Desarrollo 2008-2010 "Colombia, destino turístico de clase mundial", Plan de Desarrollo 2011- 2014 "Turismo Factor de Prosperidad para Colombia" y el Plan de Desarrollo 2014-2018 “Turismo para la Construcción de la Paz" se han planteado estrategias que han fortalecido el desarrollo del sector en cuenta a directrices gubernamentales que sirven de instrumento para el progreso de la actividad.

\section{Antecedentes del turismo comunitario en Colombia}

En nuestro país este turismo inicialmente empezó a desarrollarse en las Unidades de Parques Nacionales y Naturales; los programas de Posadas Turísticas en el 2003 y Destinos Mágicos 2005(Burgos Doria, 2015). El Gobierno nacional ve este turismo como la oportunidad de un desarrollo económico y social en el que las comunidades se organizan para prestan servicios a partir de las potencialidades culturales y naturales con las que cuentan (Ministerio de Comercio Industria y Turismo, 2011).

En 2008 surge el Movimiento OVOP como estrategia de desarrollo local que se fundamenta en el trabajo de las comunidades, que a través de productos propios y únicos se convierten en fuente de desarrollo. Esta iniciativa persigue generar transformaciones económicas y sociales en una comunidad, buscando la inclusión y que se logre una distribución más equitativa en las comunidades (Movimiento OVOP, 2011). En la actualidad este turismo se viene desarrollando en algunas comunidades como grupos étnicos y familias campesinas, entre otras, lo que ha permitido que ellas ejerzan un papel protagónico en su planificación y en su gestión, al igual que participen en la distribución de los recursos económicos que se generan.

Por su parte, el Ministerio de Comercio Industria y Turismo [MinCIT] (2011) define el turismo comunitario como:

\section{[...] la oferta de servicios turísticos,} por parte de una comunidad organizada, que participa, se beneficia e involucra en los diferentes eslabones de la cadena productiva del turismo, en busca de mayor bienestar, desarrollo y crecimiento económico, valorando las características naturales y culturales de su entorno, que les permite prestar servicios competitivos, de calidad y sostenibles. (p.13)

El Gobierno nacional, a través del MinCIT, el municipal y el liderazgo de las comunidades, ha hecho inversiones a través de proyectos en diferentes puntos del territorio nacional, lo que ha permitido de alguna manera su desarrollo. A continuación, se muestran algunas de las inversiones realizadas en los últimos cuatro años (ver tabla 2). 
Tabla 2: Inversiones de turismo comunitario en Colombia

\begin{tabular}{|c|c|c|c|c|c|c|}
\hline Región & $\begin{array}{l}\text { Subsidio del } \\
\text { Estado }\end{array}$ & $\begin{array}{l}\text { Aportes del } \\
\text { Municipio }\end{array}$ & $\begin{array}{c}\text { Aportes de la } \\
\text { Comunidad }\end{array}$ & $\begin{array}{l}\text { Aportes de la } \\
\text { Gobernación }\end{array}$ & $\begin{array}{c}\text { Otros } \\
\text { Aportes }\end{array}$ & Total \\
\hline $\begin{array}{l}\text { San Andrés } \\
\text { (12 familias) }\end{array}$ & $\$ 74.832 .180 .00$ & $\$ 43.739 .136 .00$ & $\$ 13.174 .596 .00$ & ---------------- & -------------- & $\$ 131.745 .912 .86$ \\
\hline $\begin{array}{l}\text { Providencias } \\
\text { (35 Familias) }\end{array}$ & $\$ 267.260 .000 .00$ & $\$ 76.360 .000 .00$ & $\$ 38.180 .000 .00$ & --------------- & ------------- & $\$ 381.800 .000 .00$ \\
\hline $\begin{array}{l}\text { Valle-Buena- } \\
\text { ventura-La } \\
\text { Bocana } \\
\text { (30 familias) }\end{array}$ & $\$ 171.614 .313 .00$ & $\$ 25.291 .472 .00$ & $\$ 24.693 .236 .00$ & $\$ 25.333 .333$. & ------------- & $\$ 246.932 .355 .00$ \\
\hline $\begin{array}{l}\text { Valle- Buena- } \\
\text { ventura-Juan- } \\
\text { chaco y } \\
\text { Ladrilleros }\end{array}$ & $\$ 337.508 .149$ & $\$ 49.739 .896 .00$ & $\$ 48.563 .364 .00$ & -------------- & $\$ 49.822 .222$ & \\
\hline $\begin{array}{l}\text { Bahía Solano } \\
\text { (27 Familias }\end{array}$ & $\$ 107.568 .000 .00$ & $\$ 30.733 .714 .00$ & $\$ 15.366 .857 .00$ & 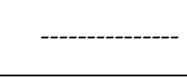 & ----- & $\$ 153.668 .571 .00$ \\
\hline $\begin{array}{l}\text { Nuquí } \\
\text { (23 familias) }\end{array}$ & $\$ 91.448 .000 .00$ & $\$ 26.128 .000 .00$ & $\$ 13.064 .000 .00$ & . & --- & $\$ 130.640 .000 .00$ \\
\hline
\end{tabular}

Fuente: Ministerio de Comercio Industria y Turismo (s.f).

\section{Inversiones y asociaciones en el desarrollo del turismo comunitario}

Para la financiación de estos proyectos el Gobierno y las entidades públicas o privadas han tenido en cuenta el componente de sostenibilidad como base fundamental para su desarrollo, en el que es importante que se tengan en cuenta aspectos de tipo:

- Ambiental: para el uso óptimo a los recursos naturales que son un elemento fundamental del desarrollo turístico.

- Sociocultural: se debe tener en cuenta el respeto y autenticidad de las comunidades anfitrionas, conservando su patrimonio cultural y sus valores tradicionales.

- Económico: que la actividad económica sea viable a largo plazo; empleo, ingresos y servicios sociales para las comunidades anfitrionas que contribuyan a reducir la pobreza.
Según convenio de cooperación establecido entre la Unidad Administrativa de Organizaciones Solidria; MinCIT, Artesanias de Colombia y Unidad de Parques Nacionales Naturales (2013), en la actualidad existen en el país organizaciones de turismo comunitario que vienen apoyando el fomento de este en algunas regiones del país, entre las que se pueden resaltar:

- La Asociación Gota Verde en Coloso, Sucre.

- Asociación Guías Tours en Coveñas, Sucre.

- Cooperativa de Tenderos.

- Asociación Comunitaria para la Promoción Cultural en Cocorná, Antioquía.

- Posadas Nativas en San Andrés Isla.

- Corporación Cemtur Tierra dentro en Inza, Cauca. 
- Corporación Comunitaria Mano Cambiada en Nuquí Choco.

- Asotrans fluvel en la Macarena Meta.

- Corporación Coremxa en Jamundí Valle.

El Movimiento OVOP en Colombia viene desarrollando proyectos de desarrollo comunitario, que contribuyen a mejorar la calidad de vida de los territorios locales, a que se fomente la cooperación y la asociatividad entre las comunidades y por último a que se generen ingresos adicionales. Entre los proyectos en los cuales la participación del Estado ha sido un aporte fundamental, encontramos los descritos en la tabla 3.

Tabla 3. Proyectos de turismo comunitario

\begin{tabular}{|c|c|c|c|}
\hline Lugar & $\begin{array}{c}\text { Características a } \\
\text { fortalecer }\end{array}$ & Plan de acción & Resultados \\
\hline $\begin{array}{l}\text { Sibundoy-Putuma- } \\
\text { yo "Agroturismo y } \\
\text { ecoturismo en reservas } \\
\text { naturales y fincas agro- } \\
\text { ecológicas" (Movimien- } \\
\text { to OVOP,2011) }\end{array}$ & $\begin{array}{l}\text { Los productos y técnicas } \\
\text { en el alto Putumayo } \\
\text { principalmente en } \\
\text { Sibundoy son un gran } \\
\text { potencial endógeno que } \\
\text { se puede unir al turis- } \\
\text { mo, las familias tienen } \\
\text { los talleres y tiendas } \\
\text { pequeños en sus casas, } \\
\text { participan en ferias loca- } \\
\text { les y no están formal- } \\
\text { mente constituidos, el } \\
\text { comercio por tanto es } \\
\text { muy limitado a la vista } \\
\text { del visitante y turista. }\end{array}$ & $\begin{array}{l}\text {-Se brindó inducción } \\
\text { para el acceso a recursos } \\
\text { del Fondo de Promo- } \\
\text { ción Turísticas, líneas } \\
\text { de apoyo, tipologías de } \\
\text { proyectos, y personas } \\
\text { de contacto. } \\
\text {-Se brindó inducción } \\
\text { para el acceso a la } \\
\text { oferta del Departamento } \\
\text { para la Prosperidad So- } \\
\text { cial, Fondo de Capacita- } \\
\text { ción micro empresarial, } \\
\text { especialmente para } \\
\text { procesos de agroindus- } \\
\text { tria y artesanías. } \\
\text {-Se motivó a la pre- } \\
\text { sentación de solicitu- } \\
\text { des a Artesanías de } \\
\text { Colombia para temas } \\
\text { del mejoramiento del } \\
\text { diseño e innovación de } \\
\text { la artesanía. } \\
\text {-Se indicó las fuentes } \\
\text { de apoyo a procesos } \\
\text { agropecuarios tales } \\
\text { como: alianzas pro- } \\
\text { ductivas, mujer rural e } \\
\text { INCODER. }\end{array}$ & $\begin{array}{l}\text { Creación y fortaleci- } \\
\text { mientos de grupos } \\
\text { interdisciplinarios para } \\
\text { la gestión del desarro- } \\
\text { llo local, apoyo en la } \\
\text { operación, seguimiento } \\
\text { y sostenimiento. } \\
\text {-Guianza Turística, } \\
\text {-Asistencia técnica en } \\
\text { senderismo y observa- } \\
\text { ción de especies nativas } \\
\text { de flora y fauna. } \\
\text {-Diseño de productos y } \\
\text { paquetes turísticos. } \\
\text {-Acompañamiento para } \\
\text { la generación de siner- } \\
\text { gias, redes y colaboracio- } \\
\text { nes entre los posaderos, } \\
\text { artesanos, restaurantes, } \\
\text { hoteles, alcaldía SENA y } \\
\text { guías de turismo. } \\
\text {-Recuperación de la } \\
\text { memoria gastronómica y } \\
\text { cultural. }\end{array}$ \\
\hline
\end{tabular}




\begin{tabular}{|c|c|c|c|}
\hline Lugar & $\begin{array}{c}\text { Características a } \\
\text { fortalecer }\end{array}$ & Plan de acción & Resultados \\
\hline $\begin{array}{l}\text { Municipio de Tu- } \\
\text { chín-Córdoba. Inicia- } \\
\text { tiva "Sombrero fino } \\
\text { vueltiao" (Movimiento } \\
\text { OVOP, 2011). }\end{array}$ & $\begin{array}{l}\text { La comercialización del } \\
\text { sombrero vueltiao, es la } \\
\text { principal obra artesanal } \\
\text { de unas } 500 \text { familias } \\
\text { de Tuchin, el cual se } \\
\text { elabora en un } 95 \% \text { en la } \\
\text { zona urbana del pueblo } \\
\text { y son los intermediarios } \\
\text { quienes llegan y fijan } \\
\text { precios }\end{array}$ & $\begin{array}{l}\text { Es importante que las } \\
\text { organizaciones líderes } \\
\text { se capaciten y fortalezca } \\
\text { sus conocimientos de } \\
\text { desarrollo local, proyec- } \\
\text { tos, costos y mercadeo } \\
\text { así mismo han solici- } \\
\text { tado acompañamiento } \\
\text { para la innovación de } \\
\text { productos conservando } \\
\text { las técnicas tradicio- } \\
\text { nales. La comunidad } \\
\text { expresa la importan- } \\
\text { cia de reconocer al } \\
\text { sombrero como icono } \\
\text { nacional y se debe llevar } \\
\text { a cabo intercambio de } \\
\text { experiencias }\end{array}$ & $\begin{array}{l}\text { La unificación de } \\
\text { precios, la calidad del } \\
\text { producto, el apoyo del } \\
\text { gobierno en cuanto } \\
\text { a la presencia del } \\
\text { producto en ferias y } \\
\text { eventos nacionales como } \\
\text { internacionales }\end{array}$ \\
\hline $\begin{array}{l}\text { Sierra Nevada del Co- } \\
\text { cuy. "Güicán y/o Chita". } \\
\text { (Calderón,2013) }\end{array}$ & $\begin{array}{l}\text { Es la cadena montañosa } \\
\text { nevada más extensa de } \\
\text { Colombia, con más de } \\
12 \text { picos nevados; es el } \\
\text { principal atractivo turís- } \\
\text { tico del Parque Nacional } \\
\text { Natural del Cocuy, en él } \\
\text { se práctica el ecoturis- } \\
\text { mo, senderismo que se } \\
\text { desarrolla por la cuenca } \\
\text { del río playita, rio que } \\
\text { nace por el descongela- } \\
\text { miento del glacial y se } \\
\text { alimenta de la esco- } \\
\text { rrentía acumulada en el } \\
\text { páramo que alberga la } \\
\text { cuenca. }\end{array}$ & $\begin{array}{l}\text { Desarrollar actividades } \\
\text { de ciclo montañismo, y } \\
\text { rappel, el acceso se rea- } \\
\text { liza desde tres sectores: } \\
\text { Ritakuwas, la Laguna } \\
\text { Grande de la sierra } \\
\text { y Lagunillas en cada } \\
\text { sector las comunidades } \\
\text { campesinas ofrecen la } \\
\text { prestación de servicios } \\
\text { turísticos como son: } \\
\text { servicios de guianzas, } \\
\text { alquiler de caballos, ali- } \\
\text { mentación y alojamien- } \\
\text { to, zonas de campin con } \\
\text { capacidad de } 10 \text { carpas. }\end{array}$ & $\begin{array}{l}\text { Actualmente es la prin- } \\
\text { cipal fuente de ingresos } \\
\text { para algunas familias } \\
\text { campesinas, que en } \\
\text { temporada alta meses } \\
\text { de diciembre a enero } \\
\text { según los registros de } \\
\text { ingresos al parque en el } \\
2009 \text { llagaron entre } 1000 \\
\text { a } 2500 \text { visitantes y en } \\
\text { semana santa alrededor } \\
\text { de } 1000 \text { visitas, en los } \\
\text { demás meses del año } \\
\text { llegan alrededor de } 100 \\
\text { a } 500 \text { personas, siendo } \\
\text { el mes de septiembre } \\
\text { el que menos ingresos } \\
\text { percibe por concepto de } \\
\text { ingresos. }\end{array}$ \\
\hline
\end{tabular}

Fuente: Elaboración propia.

\section{UBICACIÓN GEOGRÁFICA DEL ESTUDIO}

\section{Bogotá D.C}

El Distrito Capital de Bogotá está ubicado en el centro del país en la cordillera Oriental y está conformada por 20 localidades; posee suelo de expansión urbana y suelo rural. El suelo rural lo conforman las localidades de Usaquén, Chapinero, Santa Fe, San Cristóbal, Usme, Suba, Ciudad Bolívar y Sumapaz, ocho en total que corresponden a un área de 122.256,08 Ha, del total de 163.660,39 Ha del Distrito. (Tomo, V. I. I., (2009)(ver figura 1).

El turismo como actividad económica es de gran importancia para el crecimiento de 
una ciudad como Bogotá; el sector servicio contribuye principalmente a la generación de productos turísticos y a la consolidación de puestos de trabajo, por consiguiente es una actividad de mayor repercusión en el crecimiento y desarrollo de la ciudad. La demanda que se genera es amplia; el producto turístico está integrado por acciones e insumos muy diferentes y tiene una cadena de suministros grande y diversificada, y el gasto que genera en los turistas por el consumo de servicios beneficia a varios sectores, como la artesanía, el transporte, el comercio, entre otros.

En la actualidad, según el estudio realizado por Instituto Distrital de Turismo [IDT] y el Centro de Investigación de la Nacional [CID] (2013), las personas que llegan a la capital lo hacen por motivos de negocio, trabajo, recreación, vacaciones y por visitas a familiares y amigos. Como estrategia, la capital también viene desarrollando y ofertando la zona rural por los recursos naturales y culturales con los que cuenta su territorios, como es el caso de la localidad de Sumapaz, Ciudad Bolívar, Usme, entre otras.

En este sentido, las localidades de Ciudad Bolívar y Usme en la actualidad vienen desarrollando la actividad turística; esto se debe, en muchos casos, a la cercanía con el Distrito Capital y a la biodiversidad que poseen sus territorios.

\section{Localidad de Ciudad Bolívar}

Ciudad Bolívar está ubicada al sur del Distrito Capital de Bogotá; limita al norte con la localidad de Bosa; al sur, con la localidad de Usme; al oriente, con la localidad de Tunjuelito y Usme, y al occidente, con el municipio de Soacha. Tiene una extensión total de 12.998,46 (Ha), posee suelo urbano, suelo de expansión y suelo rural. Después de Sumapaz y Usme, Ciudad Bolívar está clasificada como la localidad más extensa, como la segunda localidad con mayor porcentaje. En la actualidad cuenta con 252 barrios en la zona urbana y con nueve veredas

Figura 1. Mapa localidades de Bogotá D.C.

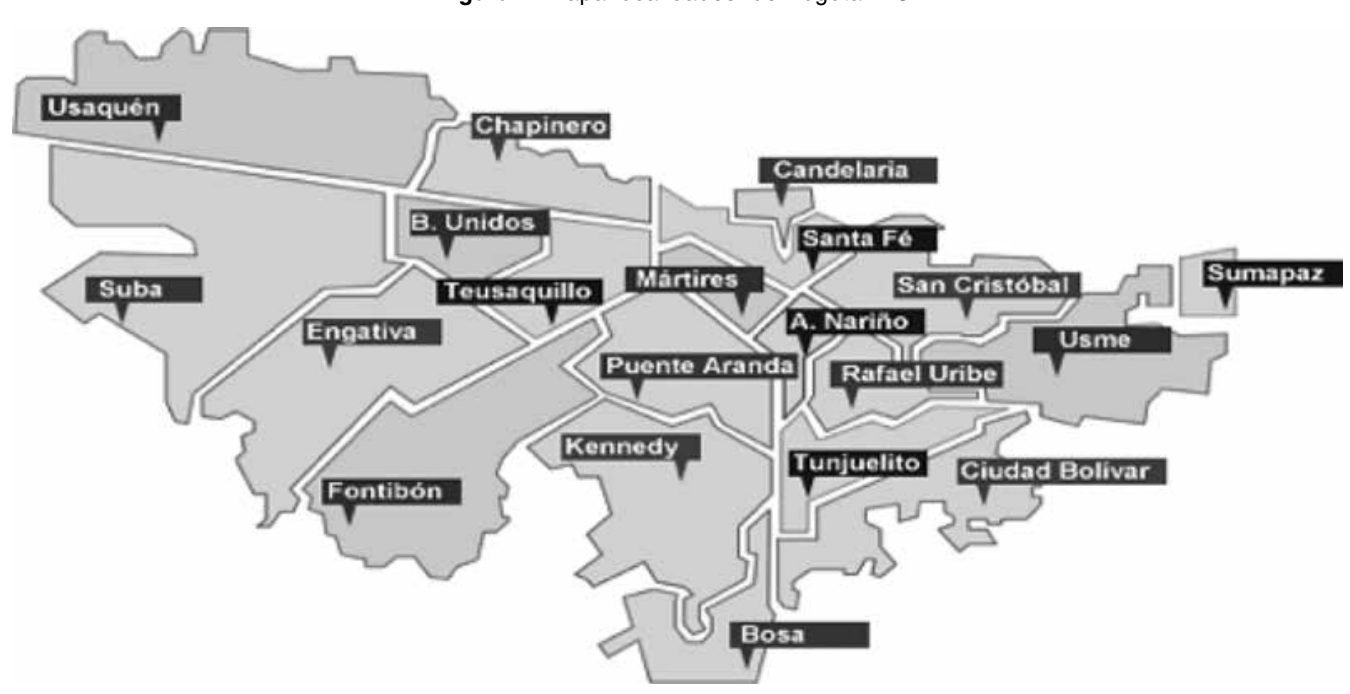

Fuente: http://somoscundinamarca.weebly.com/bogotaacute-dc.html 
en la parte rural: Quiba Alto, Quiba Bajo, Mochuelo Alto, Mochuelo Bajo, Pasquilla, Pasquillita, Santa Bárbara, Santa Rosa y Las Mercedes de Bogotá, A. M. (2004).

De acuerdo con el Plan de Ordenamiento Territorial [POT], el suelo rural se encuentra dividido en cuatro zonas de uso: Áreas para la Producción Sostenible, Parque Minero Industrial del Mochuelo, Zonas Reservadas para el Manejo y Disposición de Residuos Sólidos y aquellas que hacen parte del Sistema de Áreas Protegidas (Secretaría Distrital de Planeación, Secretaría Distrital de Ambiente, Unidad Administrativa Especial de Servicios Públicos, 2009).

En cuanto a la actividad económica, la población se dedica a la cría de ganado bovino, a la actividad agrícola, y predomina la producción de cultivos de carácter transitorio como la papa, las arvejas, las habas y, en menos cantidad, la cebolla cabezona, la cebolla junca, el maíz y algunas hortalizas y frutas de Bogotá, A. M. (2004). Sin embargo, la población viene presentando dificultades para la comercialización de los productos, la oscilación de los precios con respecto a los productos perecederos, la falta de oportunidades laborales y el poco acceso a créditos bancarios; asimismo, considera que actualmente la actividad agropecuaria ya no es tan rentable por el costo de los insumos, la baja tecnología que emplean y el abrir nuevos mercados con mejores garantías con pagos adecuados (Secretaría Distrital de Planeación, Secretaría Distrital de Ambiente, Unidad Administrativa Especial de Servicios Públicos, 2009).

Según estudios realizado por la Secretaria Distrital de Planeación (2011), la población de Ciudad Bolívar es de 639.937, de los cuales el 32,2\% —equivalente a206.198 personas - se considera pobre y el 5,9\% que equivale a 37.433 personas- se percibe en situación de indigencia. Dichas percepciones se dan con base en los ingresos que reciben (p.170). Es importante resaltar que esta localidad posee uno de los suelos rurales más ricos del Distrito Capital, por encontrarse en zona de páramo; en este sentido, cuenta con gran diversidad de recursos hídricos y posibilidades de cultivos transitorios y permanentes.

Por otra parte, el turismo es otra de las actividades que se viene desarrollando con el apoyo del Instituto Distrital de Turismo (IDT). Junto con la Fundación Natura, han desarrollado el proyecto Ruta Agroturística Los Quiches; también se impulsan otros movimientos como Senderos interpretativos ecológicos los Encenillales, que ofrece diversidad de paisajes y actividades a los visitantes con un intérprete que les sensibiliza sobre el cuidado del agua. Reconocimiento científico, Ruta de Pasquilla: sendero ecológico a la orilla del rio Tunjuelo, donde un intérprete de la zona sensibiliza sobre el cuidado del agua. Ruta de Santa Bárbara: sendero ecológico de observación del Bosque alto andino. Ruta de Mochuelo Alto: agroturismo, turismo rural comunitario.

\section{Localidad de Usme}

La localidad de Usme está ubicada al sur del Distrito Capital de Bogotá, limita al norte con las localidades San Cristóbal, Rafael Uribe Uribe y Tunjuelito; al oriente, con los municipios de Chipaque y Une; al sur, con la localidad de Sumapaz, y al occidente, con la localidad Ciudad Bolívar, con el Río Tunjuelo de por medio y los municipios de 
Pasca y Soacha (Secretaria Distrital de Planeación, ,2011). “La superficie total de Usme es de 21.506,7 hectáreas (ha), de estas 2120,7 (ha) corresponden a suelo urbano, 902,1 se clasifican como suelo de expansión urbana y las restantes $18.483,9$ ha constituyen suelo rural" (Secretaria Distrital de Planeación, 2011, p. 10).

El suelo rural de la localidad de Usme está ubicado dentro de la Reserva Forestal Protectora Bosque Oriental de Bogotá y la Reserva Forestal de la Cuenca Alta del Río Bogotá, clasificado dentro de la Estructura Ecológica Principal. Posee 16 veredas, de las cuales las de mayor extensión son Chisacá, La Unión, Los Arrayanes y Olarte. Las veredas de menor extensión son Centro Usme Rural I y II y la Requilina Rural II (Secretaria Distrital de Planeación, 2011). En él se encuentran ríos y quebradas como son los ríos Aguacilito, el Mugroso, Curubital y Chisacá, las quebradas de La Chiguaza, Olarte, La Regadera, entre otros. También hacen parte del sistema hídrico las lagunas de Boca grande, El Alar y Laguna larga; en la parte alta se encuentran las represas de La Regadera que proviene de la laguna Los Tunjos, Chisacá, y las lagunas del Boca grande, El Alar y laguna Larga (Secretaria Distrital de Planeación, Secretaria distrital de Ambiente, Secretaria Distrital de Habitat; Unversidad Distrital y Unidad Especial de servicios públicos, 2009).

Por tener una riqueza hídrica permite el refugio de una gran variedad de flora y fauna; también posee nueve áreas forestales distritales, dos santuarios de flora y fauna y tres parques ecológicos distritales de montaña, lo que sustenta que tenga gran diversidad de flora y fauna en su territorio.
En cuanto a su economía, la localidad de Usme se dedica al cultivo de maíz, a la producción de hortalizas y legumbres al aire libre, al cultivo de zanahoria, alverja, haba, cebolla cabezona, cebolla junca, alcachofa, papa, cubios y a la huerta casera. También se dedican a la producción de ganado y de especies menores. En la actualidad vienen presentado dificultad en la comercialización de los productos que obtiene de la producción agrícola y ganadera, la oscilación de los precios en los productos perecederos, la falta de oportunidad laboral, dificultad para acceder a créditos bancarios. Por último, en la actualidad vienen presentando poca rentabilidad en la actividad agropecuaria debido a los costos altos en los insumos y a la baja tecnología, entre otras. (Secretaria Distrital de Planeación, Secretaria distrital de Ambiente, Secretaria Distrital de Habitat; Unversidad Distrital y Unidad Especial de servicios públicos, 2009).

Sin embargo, según un estudio realizado en esta localidad (Secretaria Distrital de Planeación, 2011) el 34,1\%-equivalente a130.593 - personas se considera pobres y el 6,5\% - que equivale a 24,939 personasse perciben en situación de indigencia. Dichas percepciones se dan con base en los ingresos que reciben (p.171). Es importante resaltar que esta localidad posee uno de los suelos rurales más ricos del Distrito Capital, por encontrarse en zona de páramo; en este sentido, cuenta con gran diversidad de recursos hídricos y posibilidades de cultivos transitorios y permanentes.

El turismo es otra de las actividades que se viene desarrollando en la localidad, el cual es apoyado por el Instituto Distrital de Turismo (IDT), a través de proyectos de 
emprendimiento autosostenibles que a la vez les permiten obtener ingresos adicionales por su trabajo en materia de promoción turística(Burgos Doria, 2015). Entre estos los que se destacan los senderos interpretativos, el reconocimiento científico por la diversidad de recursos hídricos la flora y fauna que se encuentra en ellos, el agroturismo y el turismo comunitario en las distintas parcelas de los campesinos donde le ofertan al visitante el proceso que se requiere para el cultivo de los productos, complementándolo con la gastronomía propia de la región, y por último como atractivo cultural ofrecen visitas guiadas al cementerio muisca y las festividades de San Pedrito.

El suelo rural de las localidades de Ciudad Bolívar y Usme es un suelo muy rico para el desarrollo de diferentes actividades económicas, lo que facilitaría el progreso de la población campesina; sin embargo, se percibe falta de compromiso por parte del Estado para el impulso de nuevas organización que faciliten el acceso al empleo y para que se generen nuevos productos de consumo concebidos por los diferentes cultivos que se desarrollan es su territorio. Por lo tanto, la población dejaría de percibirse pobre y en estado de indigencia con respecto a los ingresos que perciben.

En este sentido, el turismo comunitario en el departamento de Cundinamarca viene presentado en los últimos diez años una dinámica creciente desde el punto de vista de la demanda; esto se debe a las facilidades de desplazamiento, cercanía, variedad de servicios turísticos (fiestas, gastronomía, paisajes, etc.) y a los recursos naturales y culturales con que cuentan su territorio. No obstante, es necesario promover la creación de grupos comunitarios, empresas y agencias de viajes con el propósito de vincularlos en la actividad y de esta manera desarrollar de una manera sostenible el turismo; también que permitan la articulación entre los que promocionan, los que venden y los que se encargan de direccionar la actividad en el territorio (Combariza y Aranda, 2009).

De este modo, el turismo comunitario es considerado por el Gobierno nacional como una alternativa innovadora de aprovechamiento de los recursos locales de manera sostenible, que permiten generar empleo y nuevas formas de generación de ingresos económicos a comunidades con recursos económicos limitados o excluidas, con el objeto de aprovechar las ventajas comparativas desde lo social, económico, ambiental y cultural, que con unas mínimas oportunidades y capacidades pueden transformar su realidad o entorno en oportunidades competitivas para las comunidades involucradas, y de esta manera otorgar soluciones prácticas a problemas complejos como la paz y el desarro1lo. Por consiguiente, este turismo es visto desde las políticas de Estado como una de los soluciones para el desarrollo de las zonas rurales del país (Ministerio de Comercio Industría y Turismo, 2012).

En este orden de ideas, a lo largo de esta investigación se pueden evidenciar las posturas que establece el Estado para el desarrollo del turismo comunitario y que apelan a los beneficios que ofrece a las comunidades que lo desarrollan, pero son muy pocas las estrategias que se evidencian con respecto a la gestión administrativa y de cooperación por parte del Estado a las comunidades rurales. 


\section{Amanera de Conclusión}

El turismo comunitario es uno de los caminos que conduce al desarrollo de las comunidades rurales, siempre y cuando las personas lo desarrollen como alternativa a la actividad económica a la que se dedican. También permite rescatar las costumbres tradiciones, la gastronomía y la manera de vivir de la comunidad, que son únicas en cada territorio rural. En el desarrollo de este turismo es muy importante contar con la participación de la colectividad en la gestión, la planificación, en la comercialización, la promoción y el mercadeo de sus atractivos, al igual que con el apoyo del Estado, de organizaciones no gubernamentales y de la academia en cuento a capacitaciones, al aporte de recursos económicos y las promociones, entre otros.

A partir de la revisión bibliográfica se concluye que los distintos autores consultados consideran que el turismo comunitario es una actividad que permite el desarrollo de las comunidades locales y contribuye con el empoderamiento del territorio por parte de las asociaciones que lo desarrollan, lo que facilita el cuidado de los recursos naturales y culturales con los que cuentan.

Por su parte, las localidades de Ciudad Bolívar, Usme y el Gobierno distrital vienen impulsando la actividad del turismo comunitario a través de la cooperación con organizaciones públicas y privadas; sin embargo, no se ha podido tener resultados que avancen un avance importante en este tema, pero sí se han revisado algunos desarrollos en otros países que sirven de referente en el impuso de la actividad. Por último, las comunidades de Ciudad Bolívar y Usme consideran que les falta acompañamiento y apoyo para acceder a préstamos, ya que estos están sujetos a la formalización de las actividades ante la Cámara de Comercio. Por otra parte, son conscientes de que el Gobierno distrital, al igual que el local, se han esforzado en capacitarlos con respecto a la actividad turística.

\section{REFERENCIAS}

Arriola, G. (2007). Desarrollo humano. Una introducción conceptual. PNUD. Guatemala: Argrafic.

Barrera, E. y Alvarado, O. (2009). La ruta de la sal prehispánica de zapotitlán salinas, una estrategia de desarrollo comunitario basada en los alimentos con identidad loca. Tempo - Revista Cultura, Tecnología y Patrimonio, 4(7), 33-49.

de Bogotá, A. M. (2004). Recorriendo Ciudad Bolívar 2004: diagnóstico físico y socioeconómico de las localidades de Bogotá, DC. DC Bogotá: Alcaldía Mayor de Bogotá.

Burgos Doria, R. (2015). El turismo comunitario como herramienta de emprendimiento para el beneficio de las comunidades rurales. Caso localidad de Ciudad Bolívar y Usme, zona rural de Bogotá D.C. [inédito].

Burgos, R.y Cardona, M. (2014). Turismo comunitario, como estrategias para el empoderamiento comunitario en las localidades de Ciudad Bolívar, Usme y Sumapaz, zona rural. Bogotá: Teoría y Praxis.

Cabanilla, E. (diciembre de 2015). Impactos culturales del turismo comunitario en ecuador sobre el rol del chamán y los ritos mágico-religiosos. Estudios y Perspectivas en Turismo, 24, 356-373. 
Calderon, J. y López, D. (2014). Orlando Fals Borda y la investigación acción participativa: aportes en el proceso de formación para la transformación. Centro Cultural de la Cooperación Floreal Gorini. Buenos aires. Recuperado de www. centrocultural.com

Cañada, E. y Fandiño, J. (2009). Experiencias de turismo comunitario en Nicaragua. Aportes a la economía campesina. Edutorial Edisa.

Casa, A., Soler, A. y Pastor, J. (junio, 2012). El turismo comunitario como instrumentode erradicación de la pobreza: potencialidades para su desarrollo en Cuzco (Perú). Cuadernos de Turismo, (30), 91-108.

Combariza, J. y Aranda, J. (2009). Exploración de consumo de servicios de turismo rural de la povincia rural del tequendama Colombia, a través de las agencias operadores de turismo en Bogotá. Agronomía Colombiana, 121-128.

Cox, R. (2009). Turismo indígena y comunitario en Bolivia Un instrumento para el desarrollo socio-económico e intercultural. La Paz: Plural Editores.

Fundación Codespa y Banco de Desarrollo de América Latina [CAF] (2013). Programa rutas: la apuesta por un turismo inclusivo en Latinoamérica. Madrid.

Garcia, L. (2006). El uso de marcas como herramienta para apoyar estrategias competitivas en turismo comunitario.Ginebra: Organización Internacional de Trabajo.

Guzmán, T., Borges, O. y Castillo, A. (julio- septiembre, 2011). Desarrollo económico local y turismo comunitario en países en vías de desarrollo. Un estudio de caso. Revista Ciencias Sociales RCS, XVII(3), 432-446.
Helmsing, A. y Fonseca, P. (2011). La economía política institucional del desarrollo local: dos cuentos de turismo en Brasil. EURE, 37(110), 31-57.

Instituto Distrital de Turismo [IDT] y Centro de Investigación para el desarrollo [CID] (2013). Bogotá será pionera en conocer su índice de precios del turismo. Recuperado de http://www.cid.unal.edu.co/ cidnews/index.php/noticias/2584-turismo-economia-bogota-hoteles.html.

Jimenez, T. (2014). Energías renovables y turismo comunitario: una apuesta conjunta para el desarrollo humano sostenible de las comunidades rurales. Energética, (44), 93-105.

López-Guzmán, T. y Sánchez Cañizares, S. (2009). Desarrollo socioeconómico de las zonas rurales con base en el turismo comunitario. Un estudio de caso en Nicaragua. Cuadernos de desarrollo rural, 6(62), 81-97.

Maldonado, C. (2005). Pautas metodológicas para el análisis de experiencias de turismo comunitario.Ginebra: Organización Internacional del Trabajo [OIT].

Max-Neef, M. A. (1993). Desarrollo a escala humana (2da. edición). Montevideo: Nordan-Comunidad.

Maydana, D. y Lima, P. (2012). Turismo comunitario en el parque nacional sajama $y$ zonas aledañas. La Paz.

Ministerio de Comercio,Industria y Turismo (2011). Lineamientos de políticas de turismo comunitario. Bogotá: autor.

Ministerio de Comercio Industría y Turismo (2012). Lineaminetos de política para el desarrollo del turismo comunitario en Colombia. Bogotá: autor.

Ministerio de Comercio Exterior. (s.f). Acciones del viceministerio de turismo con comunidades negras, afrocolombianas, raizales 
y palanqueras. Recuperado de file://C:/ Users/Downloads/Ministerio_de_Comercio_Exterior\%20(3).pdf

Montoya, M. (2013). Turismo comunitario y dearrollo local. Interacción y escalamiento de innovación.Lima: Instituto de Estudios Peruanos [IEP].

Montoya, M. (2013). Turismo comunitario y desarrollo rural. Interacción y escalamiento de innovaciones. Lima [edición digital].

Morales, H. (marzo-julio, 2006). Turismo comunitario: Una alternativa de desarrollo indigena. Revista de Antropología Ibercamericana, 249-264. (incluir número y volumen si los tiene la revista)

Moreno, E. y Ochoa, F. (2011). Turismo sostenible, cadena de valor y participación comunitaria en suesca (cundinamarca), colombia.Anuario Turismo y Sociedad, (12), 197-214

Movimiento OVOP. (2011). Movimiento Une Village, One Product-OVOP(Camino a la prosperidad, Elementos básicos sobre el movimiento OVOP en Colombia. Bogotá. Recuperado de https:/ovop.dnp.gov.co/ Publicaciones/ProyectoOVOP.aspx

Neide, L. y Cioce, C. (2013). Territorios solidarios de américa latina y turismo comunitario en rebote a los mega empreemdimentos transnacional. Iberoamericana de Turismo, 3(1), 4-15.

Nel-Lo, M. (2008). Organización y características del turismo rural comunitario en Costa Rica. Anales de Geografía, 28(2), 167-188.

Organización Internacional del Trabajo [OIT] (2008). Gobiernos locales, turismo comunitario y sus redes. $V$ Encuentro Consultivo Regional (REDTURS). Ginebra.

Pastor, J., Jurado, C. y Domingo, A. (2011). Desarrollo rural a través del turismo comunitario. análisis del valle y cañón de colca. Gestion Turistica, (15), 1-20.

Pastor, M., Gómez, D.y Espeso, M. (2012). Turismo comunitario y sus consecuencias entre los lacandones de Chiapas. Organismos y sistemas de apoyo. Pasos. Revista de Turismo y Patrimonio Cultural, (10), 23-43.

Programa de las Naciones Unidas para el Desarrollo [PNUd] (1990). Desarrollo humano. Bogotá: Tercer Mundo Editores.

Programa de las Naciones Unidas para el Desarrollo [PNUD] (2005).Hacia una Colombia equitativa e incluyente informe de Colombia, objetivos de desarrollo del mileniolenio 2005. Bogotá: autor.

Ramírez, D. C. (2014). La participación como base del turismo comunitario y el manejo de los recursos de uso común. Sendero de Ritakuwas, Sierra Nevada de El Cocuy, Güicán y/o Chita. Boyacá, Colombia. Turismo y Sociedad, 15, 17-28. Rodrigues, D., Corbari, S., Cioce, C. y Jurema, I. (2014). Turismo comunitario en favelas. Un estudio del favelas Inn Hostel, Chapéau Mangueira- Rio de Janeiro, Brasil. Estudios y Perspectivas en Turismo, 23(4), 786-804.

Román, M. y Ciccolella, M. (2009). Turismo rurale en Argentina. concepto, situación y perspectivas. Buenos Aire: Instituto Interamericano de cooperación para la Agricultura.

Salas, A. (septiembre, 2011). Estudio de la mini ruta turística: lita y las siete cascadasy el impacto del turismo comunitario y rural en el desarrollo de la economía local. Kalpana, (6), 13-23.

Santana, C. y Atiencia, M. (diciembre de 2013). Turismo comunitario en el cantón guayaquil. estudio de caso "cerrito de los morreños". TURyDES, 6(15). 
Secretaria Distrital de Planeación (2011). 21Monografias de las localidades Distrito Capital. Localidad de Usme. Bogotá. Recuperado de http://www.sdp.gov.co/ portal/page/portal/PortalSDP/InformacionEnLinea/InformacionDescargableUPZs/Localidad\%205\%20Usme/ Monograf\%EDa/5\%20USME\%20monografia\%202011.pdf

Secretaria Distrital de Gobierno. (s.f.). Mapa de Bogotá con las localidades. Recuperado de http://www.gobiernobogota.gov. co/quienes-somos/alcaldias-locales/ bogota-y-sus-localidades.

Sen, A. (2000). Desarrollo y libertada.Barcelona: Planeta.

Skewes, J., Henríquez, C.y Pilquimán, M. (2012). Turismo comunitario o de base comunitaria: una experiencia alternativa de hospitalidad vivida en el mundo mapuche. Tralcao sur de Chile. Cultur, 6(2), 73-85.

Suarez, R., Bribiescas, F.y Villanieva, J. (marzo de 2013 ). Gestión y fortalecimiento de proyectos comunitarios: una opción para el desarrollo turístico sustentable en comunidades rurales del estado de chihuahua (caso ejido ojo de la casa). European Scientific Journal, 9(8), 270-283.

Torres Obando, J. O. (2015). Turismo comunitario y su estudio: reflexiones desde un enfoque cultural propositivo para el desarrollo rural. Humanismo y cambio social, 5(5).

Unidad Administrativa de Organizaciones Solidria, Ministerio de Industria, Turismo y Comercio, Artesanías de Colombia, Unidad de Parques Nacionales Naturales (2013). Asociatividad para el desarrollo sostenible del sector artesanal, ecoturistico, y de turismo comunitario en Colombia. Bogotá-Colombia. Recuperado de http://www.citur.gov.co/LinkClick. aspx?fileticket=higTWrqHF4Y\%3D\&tabid $=253$

Villate, R. (2012). Desarrollo local y conservación de tortugas marinas en Costa Rica y Panamá. Una publicación semestral Derechos reservados Edición impresa de este número, Cuernavaca, México, 37.

Yanza, E. (junio-noviembre,2012). Diseño de un modelo de desarrollo ecoturístico comunitario en la zona rural de Coroneo, Sur de Gto. Revista Electrónica de Divulgación de la Investigación, 3, 1-26. 